Accepted for publication in Building \& Environment, March 16, 2013

\title{
Rain water runoff from porous building facades: implementation and application of a first-order runoff model coupled to a HAM model
}

\author{
Thijs Van den Brande ${ }^{\mathrm{a}, *}$, Bert Blocken $^{\mathrm{b}}$, Staf Roels ${ }^{\mathrm{a}}$ \\ ${ }^{a}$ Building Physics Section, KU Leuven, Kasteelpark Arenberg 40 bus 2447, B-3001 \\ Leuven, Belgium \\ ${ }^{b}$ Building Physics and Services, Department of the Built Environment, Eindhoven \\ University of Technology, Eindhoven, The Netherlands
}

\begin{abstract}
Wind-driven rain (WDR) is one of the most important moisture sources for a building facade. Therefore, a reliable prediction of WDR loads is a prerequisite to assess the durability of building facade components. However, current state of the art Heat-Air-Moisture (HAM) models that are used to assess the moisture behaviour of building facades are still based on several simplifications. Important phenomena of WDR such as raindrop impact, absorption, evaporation and runoff are not yet taken fully into account. This paper presents the implementation and application of a rainwater runoff model coupled to a 2D HAM model. In the first part of the paper, the runoff model itself is briefly described and implemented. In the second part, the coupled runoff-HAM model is used to calculate absorption and runoff of WDR during a two-shower rain event on two different types of porous facades with different capillary absorption coefficient and capillary moisture content. The calculation is performed with a realistic distribution of the impinging WDR intensity, based on CFD simulations, and with meteorological data, on a 10minute basis. The impinging rain water that cannot be absorbed by the material develops a water film on the surface and runs down along the wall. It is shown that runoff of WDR can have significant influence on the moisture behaviour of the facade, e.g. materials with low capillary absorption coefficients may absorb almost double the amount of impinging wind-driven
\end{abstract}

\footnotetext{
${ }^{*}$ Corresponding author. thijs.vandenbrande@bwk.kuleuven.be, +32 16321348
} 
rain when including runoff. Also the moistening time of the facade was to be found extended. To conclude some important notes are given for future development of runoff models.

Keywords: Heat-Air-Moisture transfer modelling, Moisture runoff, Biocide leaching, Driving rain, Building envelopes

\section{Nomenclature}

A capillary absorption coefficient $\left(\mathrm{kg} / \mathrm{m}^{2} \sqrt{\mathrm{s}}\right)$

$K$ moisture permeability (combined liquid and vapour) $(s)$

$K_{l} \quad$ liquid moisture permeability $(s)$

$R H_{e} \quad$ outdoor relative humidity (-)

$R_{h} \quad$ horizontal rainfall intensity $(\mathrm{mm} / \mathrm{h})$

$T_{e} \quad$ outdoor temperature $\left(^{\circ}\right)$

$U_{10}$ reference wind speed at $10 \mathrm{~m}$ height $(\mathrm{m} / \mathrm{s})$

$\beta \quad$ surface vapour transfer coefficient $(s / m)$

$\delta_{v} \quad$ vapour permeability $(s)$

$\gamma \quad$ surface tension at the liquid-air interface $(\mathrm{N} / \mathrm{m})$

$\nu \quad$ kinematic viscosity $\left(\mathrm{m}^{2} / \mathrm{s}\right)$

$\rho \quad$ density of water $\left(\mathrm{kg} / \mathrm{m}^{3}\right)$

$\theta \quad$ angle of inclination of the surface $\left(^{\circ}\right)$

$\theta_{N} \quad$ wind direction $\left({ }^{\circ} N\right)$

$g \quad$ gravitational acceleration $\left(9.81 \mathrm{~m} / \mathrm{s}^{2}\right)$

$h \quad$ height of the liquid film $(m)$

$p_{c} \quad$ capillary pressure $(P a)$

$p_{v} \quad$ vapour pressure $(\mathrm{Pa})$ 
$t \quad$ time $(s)$

$u \quad$ streamwise velocity component $(\mathrm{m} / \mathrm{s})$

$w \quad$ moisture content $\left(\mathrm{kg} / \mathrm{m}^{3}\right)$ 


\section{Introduction}

Increased moisture levels in porous building materials can result in important problems for the durability of the building facade. At the outside of the facade, it contributes to damage due to freeze-thaw cycles (Fig. 1(a)), surface soiling, dirty- and white washing of facades [1-3] as depicted in Fig. 1 (b), leaching of nanoparticles into the environment $[4,5]$, discoloration by efflorescence (Fig. 1(c)) and moisture induced salt migration [6, 7]. In case of bad workmanship or design, it can also contribute to water penetration (damage depicted in Fig. 1(d)) or biological damage such as fungal and mould growth at the inside of the facade (Fig. 1(e)). Of all moisture sources to which building facades can be exposed, wind-driven rain (WDR) can be considered as one of the most important [3, 8]. Abuku et al. [9], for example, indicated that WDR loads on a tower with solid brick facades can result in an increased mould grow risk at the inside wall surface, an increased energy consumption and a more humid indoor climate. Although the above mentioned problems are widely recognized for a long time, repair and replacement costs are still rising, accompanied by damage claims. A reliable description of WDR and its corresponding damage effects can thus contribute to addressing these issues and to the development of sustainable building facades and indoor environments.

In the past decades, much attention has been attributed to the prediction of impinging WDR loads on building facades. Previous research efforts

mainly focused on predicting the impinging WDR intensity on the building facade using measurements, semi-empirical formulae and numerical simulations with Computational Fluid Dynamics (CFD). An extensive overview can be found in [3]. To assess the moisture behaviour of building components, this information needs to be combined with a Heat-Air-Moisture (HAM) model. In the past years, extensive and powerful HAM models have been developed and their application has become firmly established. Most of these models take the impingement and absorption of WDR on building facades into account [10-15]. However, the so-called "secondary effects" of WDR, such as splashing and bouncing of raindrops [14-17] and the runoff of moisture along the surface, have, to the best of our knowledge, not yet been implemented in HAM models. This paper will address runoff that occurs whenever the moisture supply due to WDR exceeds the maximum absorption rate at the material surface. 


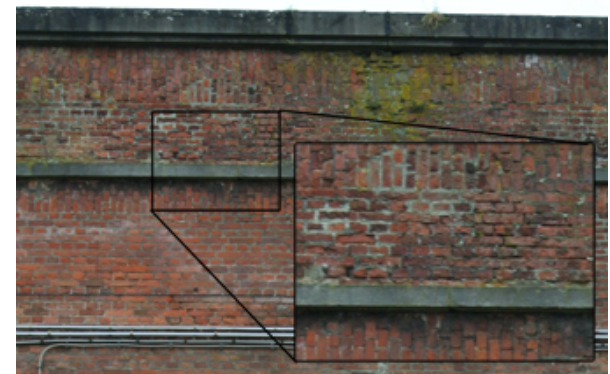

(a)

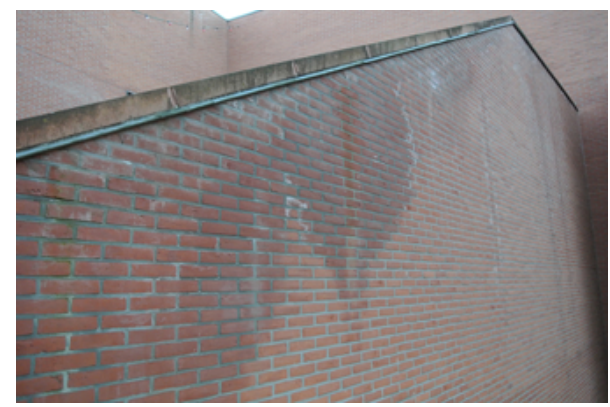

(c)

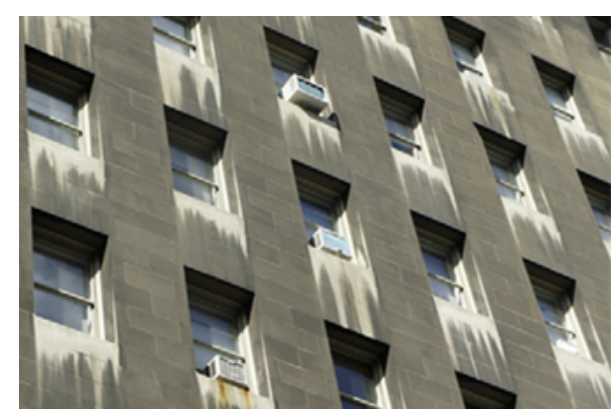

(b)

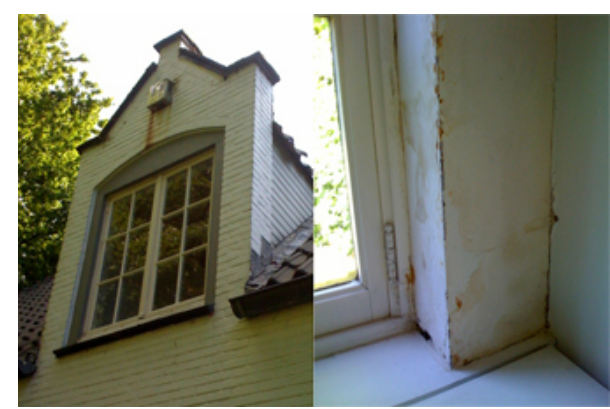

(d)

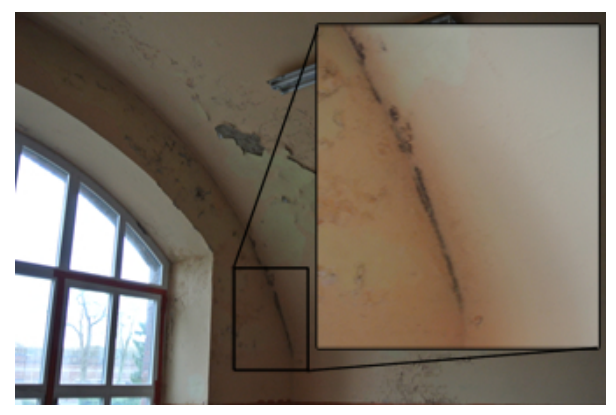

(e)

Figure 1: Damage effects due to WDR. (a) weathering of a brick wall of the military training facility, Diest, Belgium (b) Surface soiling on a contemporary building, where the dark area represent the soiled surface and the light areas the cleaned surface by runoff, (c) efflorescence on a brick wall in Leuven, Belgium (d) a detail from a house in Antwerp Belgium, where due to bad design, rain infiltrates at the top of the window, resulting in moisture damage at the inside, (e) mould growth and aesthetic deterioration at the inside of the military training facility, Diest, Belgium. 
Although several previous studies have focused on rainwater runoff, they were mainly of the experimental [18] - and/or observational type [1]. Numerically, runoff was recently studied in combination with a simplified absorption model [19]. To the best of our knowledge, up to now no attempt has been made to numerically study WDR absorption and runoff with state-of-the-art HAM models. In these existing HAM models, the modelling of moisture flow is based on capillary pressure or moisture content gradients and WDR is imposed as a moisture flux at the boundary. When saturation at the boundary is reached, the boundary condition is changed from a Neumann to a Dirichlet boundary condition [13]. The development of liquid film flow that might wet underlying parts is then disregarded.

Liquid film flow has been extensively studied in other disciplines, such as chemical engineering and biology. Several models to calculate runoff have been developed and evaluated in the past [20-23]. In building physics however, the coupling between fluid flow on a surface and the hygrothermal behaviour of the wall has, to the authors' knowledge, only been made by [19] for liquid films in combination with a very simplified rain absorption model [24].

In order to model runoff on building facades it is necessary to couple three models: (1) A WDR impingement model; (2) a state-of-the-art HAM model; and (3) a runoff model. Given the different time scales associated with these phenomena a two-step approach is proposed in this paper. First a quasi steady-state method is used to calculate the amount of WDR on the facade for ten-minute intervals. Second, a staggered solution procedure is used to incorporate the interaction between the liquid film flow and the absorption process. For the second part, this paper presents the extension of a state-of-the-art HAM model with a runoff model.

Sections 2 and 3 describe the coupling of the runoff model, based on the Nusselt solution for fluid flow along an inclined plane, with an existing HAM model. The limitations of the Nusselt solution, the important required changes to the boundary conditions and the numerical implementation of the film flow are outlined. In section 4, a simulation example is described of an cubic building with a concrete and brick facade finishing. This example is used to explain the proposed methodology and to show the impact of runoff 
on the wetting and drying behaviour of building facades. 


\section{Film flow along inclined planes}

\subsection{The lubrification equation}

In order to highlight the possibilities and limitations of the Nusselt solution [25], the approach by Ruyer-Quil et al. [21] and later adopted by Blocken and Carmeliet [19] is presented in this section. A fluid flow is classified as free surface flow when it has at least one boundary with another fluid and when this other fluid has negligible influence on the fluid under study. In this case the surrounding fluid is the air and following Fan et al. [26] it seems a valid assumption for the current application that the wind flow around the building does not influence the motion of the water sheet on the facade. The near wall air speed is assumed to be smaller than the critical value $(8-12 \mathrm{~m} / \mathrm{s})$ derived by Fan et al [26].

Greenspan [27] described the motion of a small viscous droplet that wets a surface by deriving the lubrification equation (Eq. 1) from the full NavierStokes equations. The used coordinate system for this equation is depicted in Fig. 2. In this equation the growth of the runoff layer (first term) is dependent on the supply to the moisture sheet (right hand side), the effects of surface tension (second term) and gravity (third and fourth term), where the fourth term dominates the vertical flow.

$$
\frac{\partial h}{\partial t}+\frac{1}{3 \nu} \nabla\left[\gamma h^{3} \nabla\left(\nabla^{2} h\right)-\rho g \cos (\theta) h^{3} \nabla h+\rho g \sin (\theta) h^{3} \hat{x}\right]=\frac{1}{\rho} q(x, y, t)
$$

In the lubrification equation (Eq. 1), $h$ represents the thickness of the runoff layer, $t$ time, $\nu$ the kinematic viscosity of water, $\gamma$ the surface tension at the liquid-air interface, $\rho$ the density of water, $g$ the gravitational acceleration, $\theta$ the angle of inclination of the plane and $q$ the supply and sink terms.

A full review on the assumptions for the lubrification equation on planes can be found in [28]. For the derivation of Eq. 1 the reader is referred to the literature (eg. [21, 27, 29, 30]). Note that the lubrification equation does not take into account the influence of wind-driven rain impact by individual droplets on the liquid film. Instead the supply and sink terms in Equation 1 are simply added as fluxes based on the mass conservation law. However, the advantage of this more general equation is the possibility to analyse the 


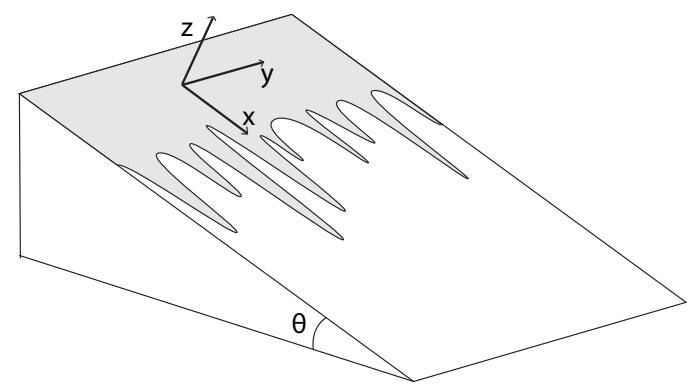

Figure 2: Orientation of the axis used in the lubrification equation.

liquid film problem in a three-dimensional space and the possibility to include surface tension. This allows further development of the runoff model to investigate fingering phenomena and runoff on smooth and non-smooth surfaces [1].

The lubrification equation is based on the following assumptions: (1) the no-slip condition between the wall and the liquid, except near the advancing and receding contact line, where including slip is necessary to solve the contact line singularity [30]; (2) at the free surface of the liquid film, the external forces are limited to constant surface tension and gravity; (3) local parallel flow without rapid changes along the film [28] and (4) the Reynolds numbers are expected to be small.

Solving Eq. 1 in the one-dimensional space $\hat{x}$ results in Eq. 2. Notice that surface tension acts through a fourth-order dissipation term in Eq. 2, giving opportunities to simplify the equation away from the boundary [30].

$$
\frac{\partial h}{\partial t}+\frac{\gamma}{3 \nu} \frac{\partial}{\partial x}\left(h^{3} \frac{\partial^{3} h}{\partial x^{3}}\right)-\frac{\rho g}{3 \nu} \frac{\partial}{\partial x}\left(h^{3} \frac{\partial h}{\partial x}\right) \cos \theta+\frac{\rho g}{3 \nu} \frac{\partial h^{3}}{\partial x} \sin \theta=\frac{1}{\rho} q(x, t)
$$

Multiple efforts have been made in literature to solve Eq. 2 to describe the liquid film and its mechanism of instability [29-31]. Attempts were made by Hocking [30] and Troian et al. [32] to solve this equation in the state of the film before transition to instability. Starting from the steady-state solution in the inner region of the film (the Nusselt solution) they derived the profile of the film using slip-models or precursor films (e.g. Fig. 3). 


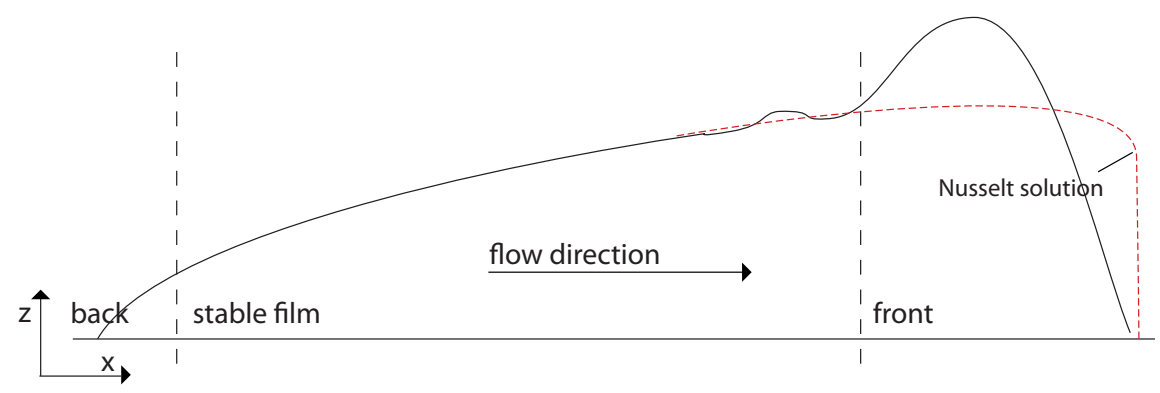

Figure 3: Profile of the liquid film before instability, based on Hocking (1990). This image is not to scale: the length of front (with a characteristic length of $\pm 5 \times 10^{-4} \mathrm{~m}$ ) and back region and the height (average height: $\pm 4 \times 10^{-5} \mathrm{~m}$ ) of the film are greatly exaggerated.

Solving Eq. 2, by using numerical discretisation schemes, is rather sensitive to divergence. High order schemes are needed to tackle large gradients in the 4th order partial differentials. This makes it less practical to implement in existing HAM models where the impinging WDR load and evaporation and absorption flows are also fluctuating in time and space. Most problems arise near the front region of the film due to the ridge shape of this front with a steep incline and decline over a short lenght (Fig.3).

\subsection{The Nusselt equation}

Huppert [29] states that the effect of the 4th order terms in Eq. 1 on the motion of contact lines and the dynamics of the fluid are expected to be small. His experiments with different silicone oils- glycerine, heavy mineral oil (HMO) and light mineral oil (LMO)- indicate that there is a good agreement with the solution of Eq. 3, which is the so-called Nusselt solution $h_{N}(4)$. Further in this paper Eq. 3 is therefore called the Nusselt equation.

$$
\begin{gathered}
\frac{\partial h}{\partial t}+\frac{\rho g h^{2}}{\nu} \frac{\partial h}{\partial x} \sin \theta=\frac{q_{w d r}-q_{a b s}-q_{\text {evap }}}{\rho} \\
u(z)=\frac{g}{2 \nu} \sin \theta\left(2 h_{N} z-z^{2}\right)
\end{gathered}
$$

The kinematic viscosity of the mineral oils are of the same order of magnitude of water. Huppert further stated that instability is mostly dependent on the surface tension. A higher surface tension leads to longer distances between the fingers and thus a more stable film. A more detailed analysis on 
the instabilities in liquid films can be found in [31, 33, 34].

Moran et al. [35] experimentally observed that the Nusselt solution (Eq. 4) slightly underpredicts the film thickness and estimates a slightly higher velocity of the film front but that it is suitable for low Reynolds numbers of the liquid flow. An analysis of these experiments in view of WDR runoff from walls can be found in [19].

By calculating the neglected terms of Eq. 2 that are a result of the effects of surface tension, the domain in which the Nusselt equation is valid can be obtained and is given by Eq. 5 [30]. This equation points out that near the tail of the film (small $x$-values) and in the early stages of film growth $(t=0)$, the Nusselt solution is less suitable.

$$
t-\frac{\gamma^{2} \nu}{(\rho g \sin \theta)^{3}} x^{-5} \geq 0
$$

In summary, in the case of runoff of impinging WDR, based on literature it seems acceptable to use the Nusselt equation to describe the film flow on a plane in terms of the position of the front and the average height of the liquid film in spite of its assumptions: (1) the liquid film should be thin enough for the Reynolds number to be small. At higher Reynolds numbers, the film becomes unstable which is not taken into account by the model. (2) the film should be thick enough to minimize the influence of surface forces. (3) The fluid is incompressible and Newtonian; (4) Surface tension is negligible; (5) The film is in contact with a gaseous fluid with low density and viscosity, such as air. 


\section{Numerical Model}

The simulations in this study were conducted with the finite element HAM-model HAMFEM, developed by the Building Physics Section of the KU Leuven [13]. For the present study, the original HAM code was extended and coupled with a module to calculate the runoff of rainwater on the exterior surface of the building facade. Both models are solved alternately by using a staggered procedure.

\subsection{HAMFEM model}

HAMFEM is a finite element model based on the standard partial differential equations of coupled heat, air and moisture transfer in porous building materials [36]. Because the focus of this study is on moisture transport, the temperature and air transfer equations are not included here. The moisture transfer in the material is governed by Eq. 6 .

$$
\frac{\partial w}{\partial t}=\nabla\left(K_{l} \nabla p_{c}\right)+\nabla\left(\frac{\delta_{v} p_{v}}{\rho R T} \nabla p_{c}\right)+\frac{\partial(\rho g K)}{\partial z}
$$

In this equation $w$ represents the moisture content of the material, $t$ the time, $K_{l}$ liquid moisture permeability, $p_{c}$ the capillary pressure, $\delta_{v}$ vapor permeability, $p_{v}$ the vapor pressure, $\rho$ the density of the liquid, $g$ the gravitational acceleration, $K$ the combined moisture permeability and the vertical axis is defined as z. The terms on the right hand side represent the moisture transfer due to capillary moisture transport (first term), vapour transport (second term) and gravitational forces (third term).

The moisture supply from the environment $\left(q_{e x t}\right)$ typically consists of two terms: moisture supply due to impinging rain $\left(q_{w d r}\right)$ and evaporation due to unequal vapour pressure between material surface and the surrounding air $\left(q_{\text {evap }}\right)$ and is defined by Eq. 7:

$$
q_{e x t}=q_{w d r}+\beta\left(p_{v, a}-p_{v, s u r f}\right)
$$

where $p_{v, a}$ is the vapour pressure in the air, $p_{v, \text { surf }}$ the vapour pressure at the surface of the building facade and $\beta$ the surface vapour transfer coefficient. Concerning the absorbed moisture flow $q_{a b s}$, as long as the moisture content at the surface remains below the capillary moisture content, the moisture 
flow into the material is equal to the flow imposed by the environment $\left(q_{\text {ext }}\right)$. These flows are depicted on the left hand side of Fig. 4. From the moment capillary saturation is attained (the moment the moisture supply at the boundary exceeds the possible flow into the material), the moisture flow into the material reduces to $K_{l} \frac{\partial p_{c}}{\partial n}$, in which $K_{l}$ is the liquid moisture permeability ( $\mathrm{s}$ ) and $n$ is the vector normal to the surface. At this moment, the boundary condition switches to a fixed capillary pressure $(0 \mathrm{~Pa})$. As long as a water film is present, the total moisture supply can be described by these boundary conditions. This results in the following equation [13]:

$$
q_{a b s}=\min \left(q_{e x t}, K_{l} \frac{\partial p_{c}}{\partial n}\right)
$$

As in most other existing HAM models, the excess moisture was disregarded from the calculations by the original HAM model. In the next section, this HAM model will be extended with a runoff module that uses the excess moisture to build a liquid film at the surface and to calculate the amount of runoff (Fig. 4). In the left figure the original fluxes at the boundary are depicted. The supplied WDR will be partially absorbed $\left(q_{a b s}\right)$ and evaporation at the surface of the materiale results in a drying flux $\left(q_{\text {evap }}\right)$. In the right figure the boundary fluxes of the extended model are shown. At the surface, if a liquid film is present, an adjusted moisture flux into the material is added $\left(q_{\text {runoff }}\right)$. The evaporation flux $\left(q_{\text {evap }}\right)$ takes place at the surface of the liquid film if one is present. For the part of the material where no liquid film is present the original boundary conditions apply.

\subsection{Runoff model}

The Nusselt equation is used (see Eq. 3 in section 2.2) to describe the flow of rainwater runoff along the facade. In the current simulations, only the two-dimensional case is considered and the model is restricted to a vertical wall. The solution of Eq. 3 can be found by a forward discretisation scheme in time and a backward scheme in space. This results in Eq. 9 for the film thickness where $n$ represents the time step and $i$ is the number (numbered from top to bottom) of the surface node (Fig. 5).

$$
\frac{h_{i}^{n+1}-h_{i}^{n}}{\Delta t^{n+1}}+\frac{\rho g}{3 \nu} \sin \alpha\left(\frac{\left(h_{i}^{n}\right)^{3}-\left(h_{i-1}^{n}\right)^{3}}{\Delta x_{i-1}}\right)=\frac{q_{w d r}^{n+1}-q_{a b s}^{n+1}-q_{e v a p}^{n+1}}{\rho}
$$




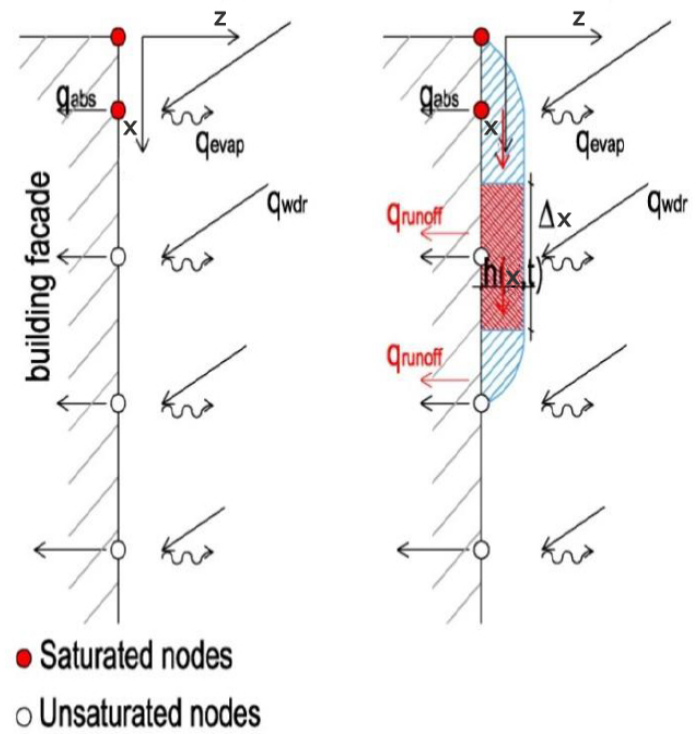

Figure 4: Coordinate system and boundary conditions for the HAM model in the coupled HAMFEM-runoff model. On the left the HAM model without including runoff is depicted, on the right the flows due to runoff are included.

The amount of moisture running down from node $\mathrm{i}$ is represented by the flow rate given by Eq. 10 that results from the Nusselt solution where $u_{i}$ represents the streamwise velocity component of the liquid flow.

$$
q_{\text {flow }, i}=\frac{\rho}{\Delta x_{i}} \int_{0}^{h} u_{i} d z=\frac{\rho^{2} g h_{i}^{3} \sin \theta}{3 \nu \Delta x_{i}}
$$

The coupled runoff model is then solved in a staggered way (Fig. 5). Within each time step, the HAM model is solved and it is checked whether a runoff layer is present or not. If present, the Nusselt Equation (Eq. 9) is solved using the flows at the boundary from the HAM model. This results in the height of the layer, the vertical runoff flow and the changed boundary conditions for the HAM model. Both are solved alternately until convergence is reached. This approach gives more insights in the moisture behaviour of the facade compared to the simplified model by Blocken and Carmeliet [19] where the material behaviour is described by the Sharp Front method described by Hall and Hoff [24]. The present coupled model allows to analyse in detail the effects of impinging WDR, the runoff layer and drying on the 


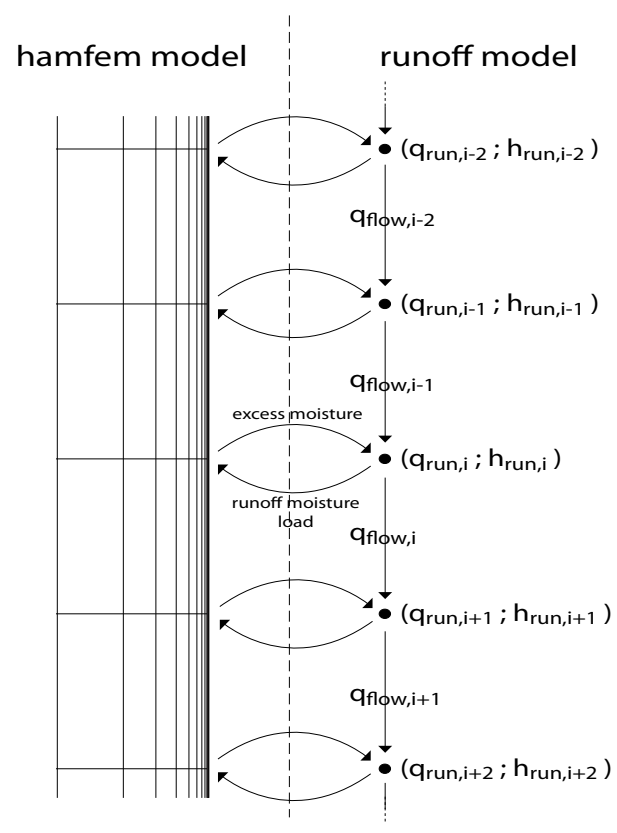

Figure 5: Staggered procedure for the coupled HAMFEM-runoff model. Within each time step, the HAM model is solved by checking whether a runoff layer is present or not. Using the flows at the boundary from the HAM model, the Nusselt Equation is then solved, resulting in the thickness of the runoff layer, the vertical flow and the changed boundary conditions for the HAM model.

moisture response of the material. The difference in time scales between the two phenomena results, though, in smaller time steps $\left(10^{-2} s\right)$ in the HAM model and thus an increased calculation time of the problem (four times slower compared to the model without runoff). 


\section{Numerical examples}

\subsection{Materials and setup}

To demonstrate the possibilities of the coupled HAMFEM-runoff model and to evaluate the importance of taking runoff into account, rain events have been simulated on a concrete facade finishing with a thickness of $20 \mathrm{~mm}$ and a height of $10 \mathrm{~m}$. Afterwards the results are compared with those of a brick facade finishing. The wall is part of a $10 \times 10 \times 10 \mathrm{~m}^{3} \mathrm{cu}-$ bic building located on a large grass plane (aerodynamic roughness length $y_{0}=0.03 \mathrm{~m}$ ) and subjected to nearly isothermal conditions. The moisture characteristics of the materials (concrete and brick) are taken from Hagentoft et al. [36] and are depicted in Fig. 6. They correspond to the following values: brick $\left(A=0.112 \mathrm{~kg} / \mathrm{m}^{2} \sqrt{\mathrm{s}}, w_{\text {cap }}=157 \mathrm{~kg} / \mathrm{m}^{3}\right)$ and concrete $\left(A=0.462 \times 10^{-3} \mathrm{~kg} / \mathrm{m}^{2} \sqrt{\mathrm{s}}, w_{\text {cap }}=146 \mathrm{~kg} / \mathrm{m}^{3}\right)$.

\subsection{Boundary and initial conditions}

A one-hour simulation run was conducted based on measured boundary conditions at the VLIET test building of the Building Physics Section at the University of Leuven [37]. The data were available at a 10-minute basis, which is about the maximum time step for WDR measurements to be valuable [38].

At the start of the simulation, the building facade is in balance with the outdoor environment. Due to this initial condition, the effects of previous moisture loads or drying periods are excluded and moisture fluxes at the facade are only dependent on the supplied WDR and the drying of the material after the shower. A specific hour of measured weather data was chosen resulting in fluctuating WDR loads, while the other boundary conditions are nearly constant. Fig. 7 shows the frequency distribution (in \%) of the horizontal rainfall intensity for different wind directions, as measured at the VLIET test building in 2010. The horizontal rainfall intensity is defined as the unobstructed rainfall intensity through a horizontal plane, as measured by a traditional rain gauge [3]. Fig. 7 also depicts that most rainfall occurs with wind from south-west. In the following, the selected period (November 27th, 2010, 09:00-10:00) is described.

The rain event consists of a one-hour period in which two short rain spells occur and with only minor deviations in outdoor relative humidity and temperature. The horizontal rain intensity is different for both spells (see Fig. 


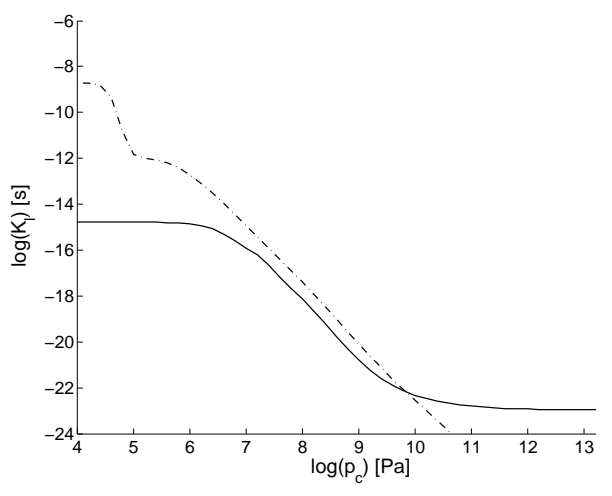

(a) liquid moisture permeability

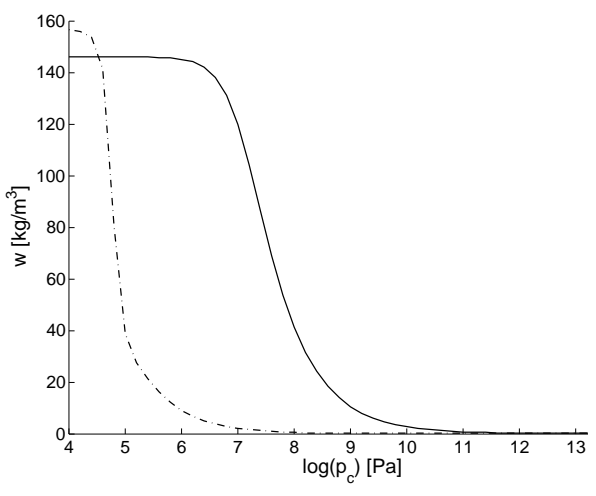

(b) moisture content

Figure 6: Material characteristics for the concrete and brick panel based on the HAMSTAD benchmark (Hagentoft et al. 2004). The full lines represent the characteristics of concrete, the dotted lines those of brick.

8). During the rain event, the average wind speed and wind direction were $5 \mathrm{~m} / \mathrm{s}$ and $200.8^{\circ}$ from North, respectively. The orientation of the facade is chosen perpendicular to this average wind direction. The average outdoor relative humidity was $92.4 \%$. The moisture transfer coefficient at the boundary $\left(\beta_{e}\right)$ was based on empirical data from Sharples [39] for the heat transfer coefficient in combination with the Lewis-analogy [13]. $\beta_{e}$ is assumed to be constant over the building height. At the back side of the panel, neither heat nor moisture exchange with the surroundings was considered which corresponds to a concrete or brick finishing on a highly insulated vapour tight layer. The micrometeorological boundary conditions are summarized in Table 1.

The catch ratios to convert these micrometeorological boundary conditions to the corresponding amount of impinging rain along the height of the wall were obtained from CFD simulations by Blocken and Carmeliet [40]. These catch ratios are a function of the reference wind speed (10 minute average wind speed) and horizontal rain intensity and therefore depend on the particular rain event. This results in two graphs for the selected period with two showers that differ in both wind speed and rain intensity. The WDR intensity along the building facade for both situations is depicted in Fig. 9. 


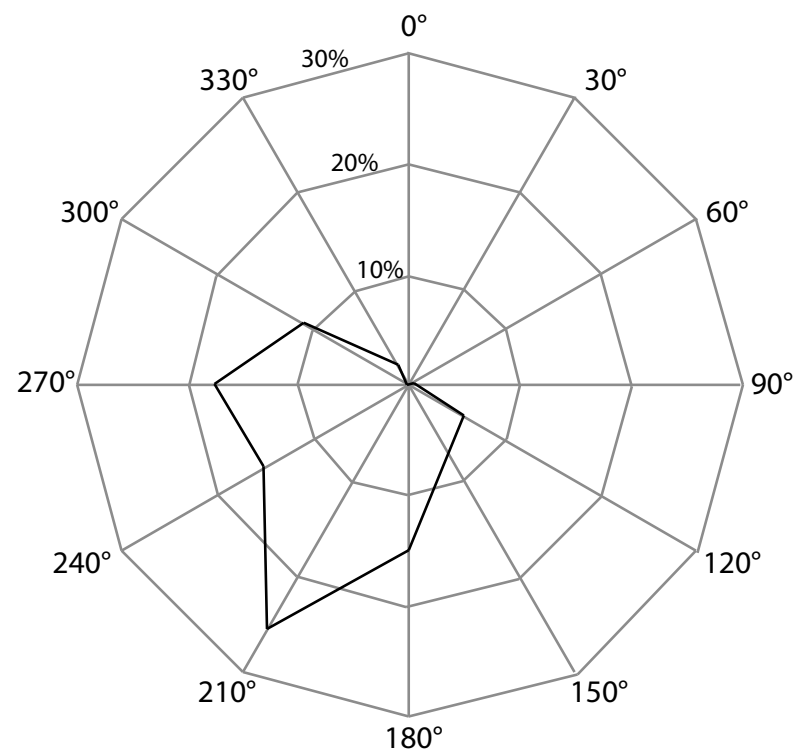

Figure 7: Frequency distribution (in \%) of horizontal rainfall intensity for different winddirections measured at the VLIET test building in 2010.

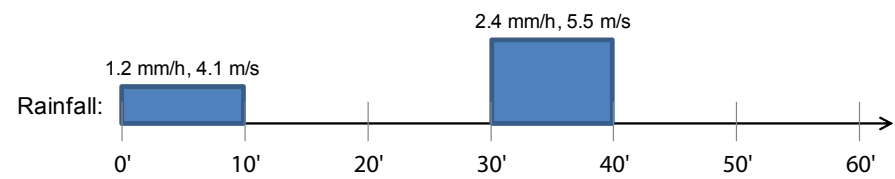

Figure 8: One hour rain event consisting of two spells, each followed by a 20 minute drying interval.

\begin{tabular}{lllllll}
\hline Time & $T_{e}\left[^{\circ}\right]$ & $R H_{e}[-]$ & $R_{h}[\mathrm{~mm} / \mathrm{h}]$ & $U_{10}[\mathrm{~m} / \mathrm{s}]$ & $\theta_{N}\left[^{\circ} \mathrm{N}\right]$ & $\beta[\mathrm{s} / \mathrm{m}]$ \\
\hline 0-10 min & 7.78 & 0.936 & 1.2 & 4.1 & 201.7 & $1.38 \times 10^{-7}$ \\
10-20 min & 8.04 & 0.924 & 0.0 & 4.8 & 198.6 & $1.55 \times 10^{-7}$ \\
20-30 min & 8.14 & 0.916 & 0.0 & 5.5 & 199.6 & $1.71 \times 10^{-7}$ \\
30-40 min & 8.24 & 0.913 & 2.4 & 5.5 & 194.5 & $1.71 \times 10^{-7}$ \\
$40-50 \mathrm{~min}$ & 8.19 & 0.924 & 0.0 & 5.2 & 206.3 & $1.64 \times 10^{-7}$ \\
50-60 min & 8.19 & 0.929 & 0.0 & 5.0 & 204.3 & $1.60 \times 10^{-7}$ \\
\hline
\end{tabular}

Table 1: Micrometeorological boundary conditions for the simulations 


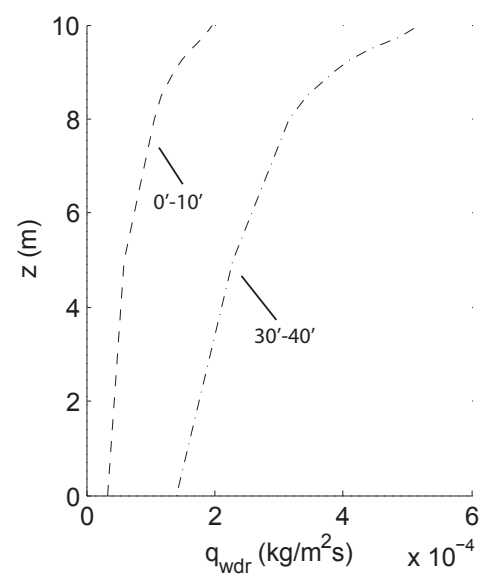

Figure 9: Impinging WDR intensity along the building facade for the first (0'-10') and second (30'-40') rain spell, derived from Blocken and Carmeliet (2006).

\subsection{Results}

In the following, the simulation results with and without the calculation of runoff are compared in order to get insights in the behaviour of a facade subjected to WDR and rainwater runoff. As mentioned earlier, a comparison with a brick facade is also made to investigate the effects of the capillary moisture transfer properties of the material. From the simulation without calculation of the moisture runoff, the amount of excess water can be deduced.

The WDR distribution, as shown in Fig. 9, yields high WDR impingement fluxes at the top of the concrete slab. The limited moisture capacity of concrete leads to quick saturation of the surface and the build-up of a runoff layer. This runoff layer strongly influences the moisture supply to the wall. This is illustrated by the average moisture content of the wall (Fig. 10). The mass increase of the wall is higher than the increase that would occur when runoff is not taken into account. As long as it rains, there is hardly any difference between the moisture content of the wall with and without a runoff layer. In the case without including runoff, the drying phase immediately starts after the end of the rain showers (after 10 minutes and after 40 minutes). In the case with runoff, drying only occurs when the water film disappeared due to runoff, absorption into the material and evaporation at the surface of the film. As a result, the wetting stage lasts longer, thus

resulting in higher moisture contents. For the current case, simulating the 


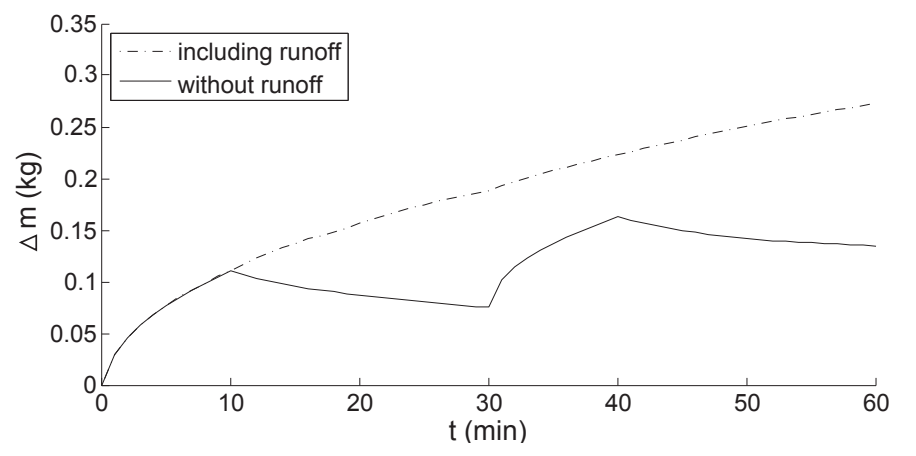

Figure 10: Mass increase of the total concrete layer subjected to a two shower rain event with (dotted line) and without including the presence of a runoff layer. From 0'-10' and from 30 '-40' the wall is subjected to wind-driven rain.

moisture behaviour of the wall without taking runoff into account underestimates the avarage moisture content of the wall after 60 ' with $45 \%$.

These effects can be analysed by focusing on the different moisture flows present at the boundary. All flows in the following are cumulative flows over the full height of the wall. In Fig. 11, the cumulative moisture flows during a one hour simulation are depicted without including runoff. Comparing the supply term and the sink terms (absorption and evaporation) indeed shows that a large amount of excess water is discarded, resulting in a mass imbalance at the surface. This led Janssen et al. [13] to expect that the excess moisture, which is disregarded by the current HAM models, might be a significant moisture source for underlying building parts which are not yet saturated. When analysing the simulation with calculation of the runoff film (Fig. 12), it can be seen that the excess moisture is used for the formation of the runoff layer. When it stops raining, the film thickness decreases by either evaporation or absorption, and these fluxes are notably higher than in the case without surface film simulation. During the rain event, the moisture layer grows (Fig. 12). Due to the large impinging WDR fluxes, this well developed liquid film runs down to the bottom of the wall, at which position it leaves the system. This is the amount that is correctly discarded from the system and it is much smaller than the amount that was discarded when not including runoff in the simulations.

The four succeeding graphs in Fig. 13 depict the growth and decline of 


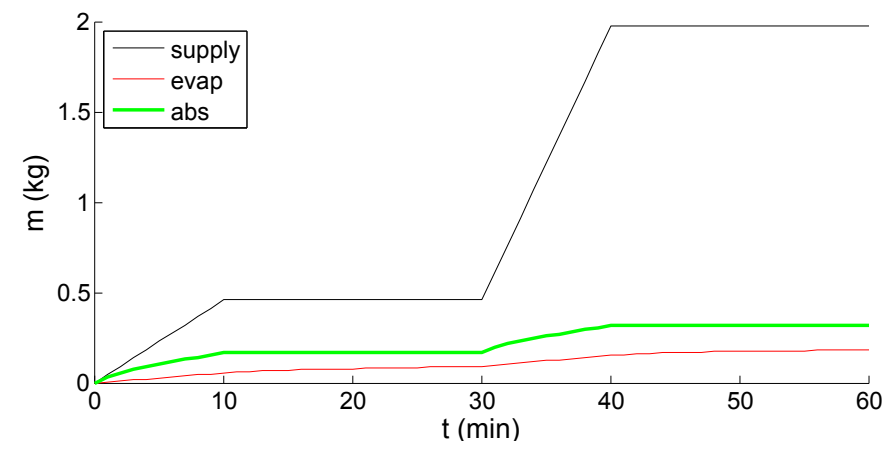

Figure 11: Cumulative moisture flows at the boundary of a concrete wall during a two shower rain event without including runoff. Note the difference between the supply and the sink (absorption and evaporation) terms. This difference is disregarded in current HAM models.

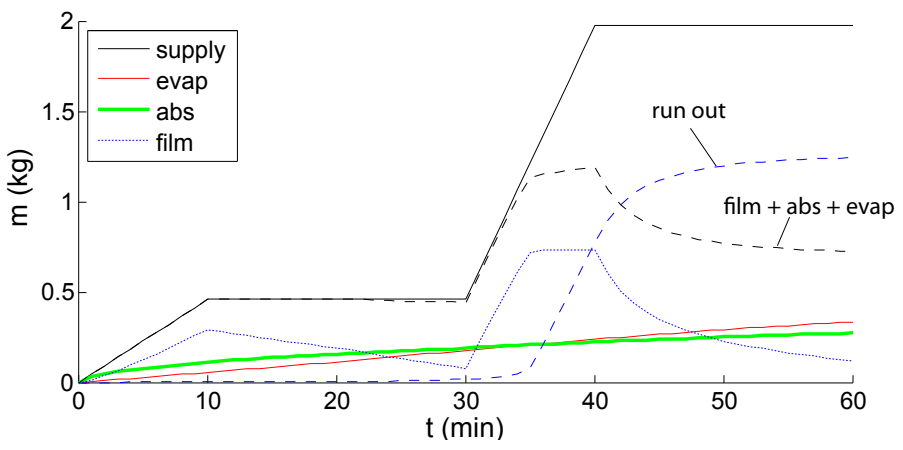

Figure 12: Cumulative moisture flows at the boundary of a concrete wall during a two shower rain event, including runoff. Note that the sink terms (absorption and evaporation), combined with the amount of liquid in the film and the amount that runs out of the system at the lowest node of the wall are equal to the supplied rain. The total mass of the evaporated water from the layer, the absorbed water and the water in the film is depicted with a dotted line. 
the runoff layer during the one-hour rain event. Due to the limited moisture capacity of the material, saturation is reached at almost the same moment along the height of the concrete slab during the first rain shower $\left(0^{\prime}-10^{\prime}\right)$. The limited moisture capacity also prohibits further absorption and a moisture film is formed over the complete height of the wall after a couple of seconds in the rain event. The excess moisture, which was originally disregarded from the HAM calculation, is used as an input for the runoff model. At first, the thickness of the moisture layer grows and the layer does not yet run down the surface. Note the more pronounced growth at the top of the wall. Once a certain film thickness is reached, the moisture layer starts to run down the facade, resulting in a thicker moisture layer at the underlying locations on the surface.

During the first drying interval, the facade remains saturated. The runoff layer extends towards lower parts and diminishes due to evaporation. After 23 minutes, the front of the layer reaches the bottom of the wall resulting in a small flow out of the system.

At the start of the second shower (30') there is still a runoff layer present at the lowest 8 meters of the wall (depicted with a bold line on Fig. 13c). Due to this presence and the new water supply, the liquid films grows rapidly and the film is already fully developed after a few minutes. There is a well developed vertical flow and this is the point where the large runoff flow out of the system occurs, as represented in Fig. 12.

The beginning of the second drying period (40'-60') is similar to the first drying period. It can be characterised by a vertical runoff flow and an evaporation term, both responsible for the shrinkage of the layer. At a certain point, the runoff flow becomes small due to the limited thickness of the runoff layer.

The presence of the moisture film has thus two effects on the wall. First the film, running down towards unsaturated surface parts, provides an additional moisture source for those parts and the average moisture content of the concrete panel increases. Second, as long as the film is present, evaporation will take place at the surface of the moisture film and thus is not decreasing the moisture content of the wall.

If the outer layer of the facade would be constructed of a brick panel no runoff layer would be present under the given conditions. Brick is able to absorb all impinging WDR. This is shown in Fig. 14 where the supplied 


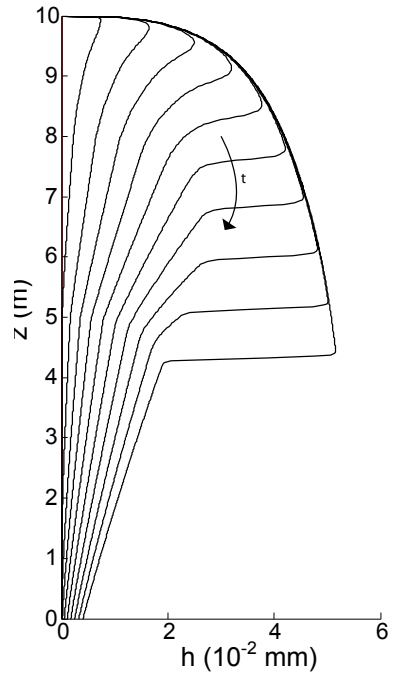

(a) 0'-10'

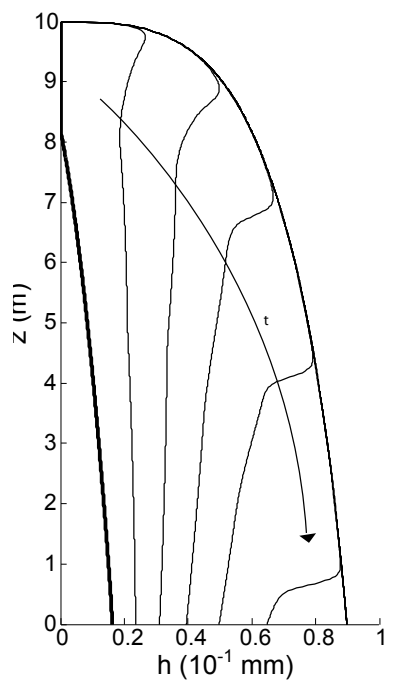

(c) $30^{\prime}-40$ '

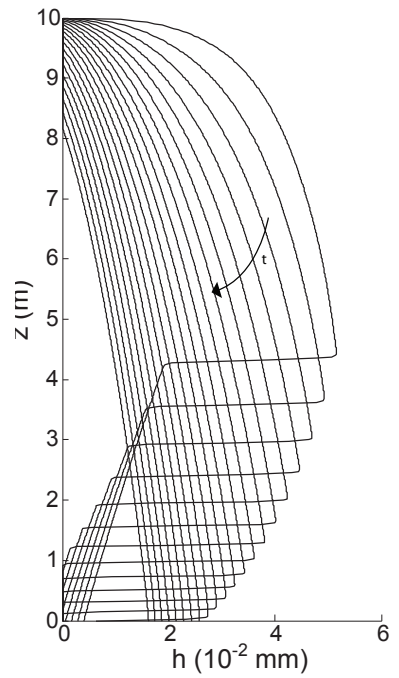

(b) 10'-30'

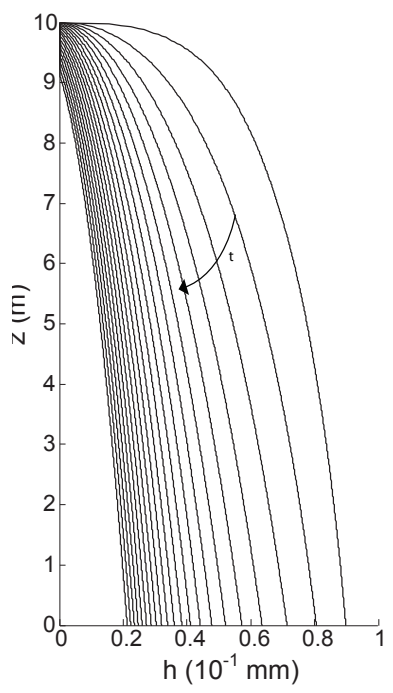

(d) 40'-60'

Figure 13: Height of the runoff layer $(\mathrm{h})$ along the height of the facade $(\mathrm{z})$ during a one hour rain event with two showers (0'-10' and 30'-40'), followed by a drying period (10'-30' and 40'-60') where the bold line in figure c shows the runoff layer present at the start of the second shower (at $\left.t=30^{\prime}\right)$. Each line in these figures represents the height of the film at a given time. The distance between two neighbouring lines corresponds to a time period of 60 seconds. 


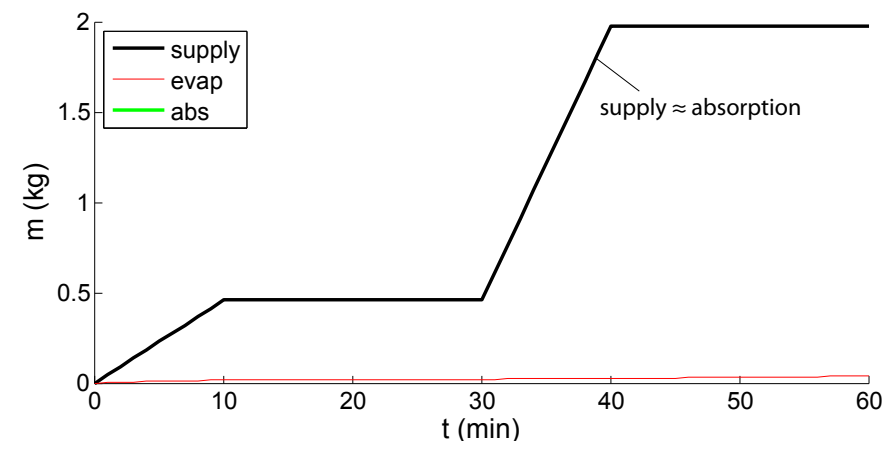

Figure 14: Cumulative moisture flow on a brick wall during a two shower rain event. The total amount of supplied moisture is absorbed by the brick wall and no runoff layer appears.

moisture load due to WDR is completely absorbed. Over time the supplied moisture evaporates from the brick. For this kind of facade materials, larger moisture loads are needed to trigger runoff. 


\section{Discussion and conclusion}

In this paper, a state-of-the-art HAM model (HAMFEM), was extended with a first order runoff model. To do so, an extra node for each boundary node was added where the liquid film was evaluated. Excess moisture that could not be absorbed was converted to contribution to the liquid film at this node. The development and runoff of the liquid film was calculated using the Nusselt equation. By a staggered procedure the interaction of the liquid runoff film and the building facade could be studied.

Using a two dimensional simulation example, it was found that the incorporation of runoff can strongly influence the moisture content of a wall. The influence is however greatly dependent on the supplied WDR and the material characteristics. In addition it was found that a runoff film is not likely to appear on materials with a large potential for capillary transport.

When runoff occurs, the mass increase of the facade due to WDR can double compared to that of the same facade under the same WDR without including runoff. For facade materials with low liquid moisture permeability, disregarding runoff can result in an underestimated absorption and thus an underestimated average moisture content of the facade. This can mainly be attributed to the fact that the presence of a runoff layer delays drying of the facade during the first minutes after the rain event and results in an increased moisture flow towards areas that are not yet saturated. In order to capture the effects of consecutive wetting and drying phases, a state-of-the-art HAM model was used that is able to define the liquid moisture permeability in relation to the moisture content of the facade. This more detailed approach, compared to the analytical Sharp Front model, resulted in higher flows at local pre-wetted parts of the facade.

The coupled model and the calculations presented in this paper have some important limitations. First, the surface vapour transfer coefficients used to calculate the evaporation rate were based on the Lewis analogy and this coefficient was assumed to be constant along the wall, although in reality spatial gradients will be present [41]. Second, due to using the Nusselt solution for the runoff layer, film front instability and film fingering was not included. Third, at this moment the lack of complete and detailed experimental data sets impedes validation of the coupled model. Note however that both mod- 
els themselves (HAM model and runoff model) were validated [42, 19].

The future development of this model can be twofold. Although early validation efforts based on the experiments of Beijer [19] supported the presently used runoff model, the coupled model as a whole would benefit from validation based on much more detailed experimental datasets. Therefore, in the later stages of the present research project, a measurement campaign focusing on runoff on porous building materials will be performed. Second due to the fact that solving the full equation for a liquid film requires quite some computational power, well considered assumptions were made to use the Nusselt solution to simulate the moisture runoff. In order to include effects at the front of the liquid film -and thus to model e.g. fingering phenomenon- a more suited solution of the basic lubrification equation is needed. 


\section{Acknowledgements}

The results presented in this paper have been obtained in the framework of the research project FWO G.0448.10N, Strategies for moisture modelling of historical buildings in order to reduce damage risks, funded by the FWO-Flanders. The FWO-Flanders (Research Fund-Flanders) supports and stimulates fundamental research in Flanders (Belgium). Their financial contribution is gratefully acknowledged.

\section{References}

[1] Küntz M, van Mier J. Gravity-driven wetting front instability of water runoffs on concrete structures. HERON 1997;42(4):231-44.

[2] Etyemezian V. Impingement of rain drops on a tall building. Atmospheric Environment 2000;34(15):2399-412.

[3] Blocken B, Carmeliet J. A review of wind-driven rain research in building science. Journal of Wind Engineering and Industrial Aerodynamics 2004;92(13):1079-130.

[4] Kaegi R, Ulrich A, Sinnet B, Vonbank R, Wichser A, Zuleeg S, et al. Synthetic TiO2 nanoparticle emission from exterior facades into the aquatic environment. Environmental pollution 2008;156(2):233-9.

[5] Kaegi R, Sinnet B, Zuleeg S, Hagendorfer H, Mueller E, Vonbank R, et al. Release of silver nanoparticles from outdoor facades. Environmental pollution 2010;158(9):2900-5.

[6] Charola A. Salts in the deterioration of porous materials: an overview. Journal of the American Institute for Conservation 2000;39(3):327-43.

[7] Brocken H, Nijland TG. White efflorescence on brick masonry and concrete masonry blocks, with special emphasis on sulfate efflorescence on concrete blocks. Construction and Building Materials 2004;18(5):31523.

[8] Karagiozis A, Hadjisophocleous G, Cao S. Wind-driven rain distributions on two buildings. Journal of Wind Engineering and Industrial Aerodynamics 1997;67-68:559-72. 
[9] Abuku M, Janssen H, Roels S. Impact of wind-driven rain on historic brick wall buildings in a moderately cold and humid climate: Numerical analyses of mould growth risk, indoor climate and energy consumption. Energy and Buildings 2009;41(1):101-10.

[10] Künzel HM. Simultaneous heat and moisture transport in building components. one- and two-dimensional calculation using simple parameters. Ph.D. thesis; Fraunhofer Institute of Building Physics; 1995.

[11] Künzel HM, Kiessl K. Calculation of heat and moisture transfer in exposed building components. International Journal of Heat and Mass Transfer 1996;40(1):159 -67.

[12] Blocken B, Roels S, Carmeliet J. A combined CFDHAM approach for wind-driven rain on building facades. Journal of Wind Engineering and Industrial Aerodynamics 2007;95(7):585-607.

[13] Janssen H, Blocken B, Carmeliet J. Conservative modelling of the moisture and heat transfer in building components under atmospheric excitation. International Journal of Heat and Mass Transfer 2007;50(56):1128-40.

[14] Abuku M, Janssen H, Poesen J, Roels S. Impact, absorption and evaporation of raindrops on building facades. Building and Environment 2009;44(1):113-24.

[15] Abuku M, Blocken B, Roels S. Moisture response of building facades to wind-driven rain: Field measurements compared with numerical simulations. Journal of Wind Engineering and Industrial Aerodynamics 2009;97(5-6):197-207.

[16] Reis NC, Griffiths RF, Santos JM. Numerical simulation of the impact of liquid droplets on porous surfaces. Journal of Computational Physics 2004;198(2):747-70.

[17] Erkal A, DAyala D, Sequeira L. Assessment of wind-driven rain impact, related surface erosion and surface strength reduction of historic building materials. Building and Environment 2012;57:336-48.

[18] Beijer O, Johansson A. Driving rain against externall walls of concrete [Slagregn mot betongfasader]. Tech. Rep.; Swedish Cement and 
Concrete Research Institute at the Institute of Technology; Stockholm; 1977.

[19] Blocken B, Carmeliet J. A simplified numerical model for rainwater runoff on building facades: Possibilities and limitations. Building and Environment 2012;53:59-73.

[20] Dussan E, Chow RTP. On the ability of drops or bubbles to stick to nonhorizontal surfaces of solids. Journal of Fluid Mechanics 1983;137:1-29.

[21] Ruyer-Quil C, Manneville P. Modeling film flows down inclined planes. The European Physical Journal B 1998;6(2):277-92.

[22] Ruyer-Quil C, Manneville P. Improved modeling of flows down inclined planes. The European Physical Journal B 2000;15:357-69.

[23] Savva N, Kalliadasis S. Dynamics of moving contact lines: A comparison between slip and precursor film models. EPL (Europhysics Letters) 2011;94(6):1-6.

[24] Hall C, Hoff W. Water transport in brick, stone and concrete. London and New York: Spon Press; 2002.

[25] Nusselt W. Die oberflächenkondensation des wasserdampfes. Zeitschrift VDI 1916;60(28):569 -75.

[26] Fan J, Wilson MCT, Kapur N. Displacement of liquid droplets on a surface by a shearing air flow. Journal of colloid and interface science 2011;356(1):286-92.

[27] Greenspan H. On the motion of a small viscous droplet that wets a surface. J Fluid Mech 1978;84(1):125-43.

[28] Oron A, Davis S, Bankoff S. Long-scale evolution of thin liquid films. Rev Mod Phys 1997;69(3):931-80.

[29] Huppert H. Flow and instability of a viscous current down a slope. Nature 1982;300:427-9.

[30] Hocking LM. Spreading and instability of a viscous fluid sheet. J Fluid Mech 1990;211:373-92. 
[31] Jerrett JM, de Bruyn JR. Fingering instability of a gravitationally driven contact line. Physics of Fluids A: Fluid Dynamics 1992;4(2):234-42.

[32] Troian SM, Herbolzheimer E, Safran Sa, Joanny JF. Fingering Instabilities of Driven Spreading Films. Europhysics Letters (EPL) 1989;10(1):25-30.

[33] Diez J, Kondic L. Contact Line Instabilities of Thin Liquid Films. Physical Review Letters 2001;(4):632-5.

[34] Kondic L, Diez J. Instabilities in the flow of thin films on heterogeneous surfaces. Physics of Fluids 2004;16(9):3341-60.

[35] Moran K, Inumaru J, Kawaji M. Instantaneous hydrodynamics of a laminar wavy liquid film. International Journal of Multiphase Flow $2002 ; 28(5): 731-55$.

[36] Hagentoft CE, Kalagasidis aS, Adl-Zarrabi B, Roels S, Carmeliet J, Hens H, et al. Assessment Method of Numerical Prediction Models for Combined Heat, Air and Moisture Transfer in Building Components: Benchmarks for One-dimensional Cases. Journal of Building Physics 2004;27(4):327-52.

[37] Desta TZ, Langmans J, Roels S. Experimental data set for validation of heat, air and moisture transport models of building envelopes. Building and Environment 2011;46(5):1038-46.

[38] Blocken B, Carmeliet J. On the errors associated with the use of hourly data in wind-driven rain calculations on building facades. Atmospheric Environment 2007;41(11):2335-43.

[39] Sharples S. Full-scale measurements of convective energy losses from exterior building surfaces. Building and Environment 1984;19(1):31-9.

[40] Blocken B, Carmeliet J. The influence of the wind-blocking effect by a building on its wind-driven rain exposure. Journal of Wind Engineering and Industrial Aerodynamics 2006;94(2):101-27.

[41] Blocken B, Defraeye T, Derome D, Carmeliet J. High-resolution cfd simulations for forced convective heat transfer coefficients at the facade of a low-rise building. Building and Environment 2009;44(12):2396-412. 
[42] Janssen H. The influence of soil moisture transfer on building heat loss via the ground. Ph.D. thesis; KU Leuven; 2002. 